\title{
Viability qPCR, a new tool for Legionella risk management
}

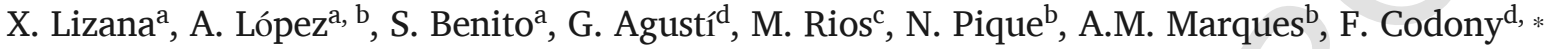 \\ a Aconsa, SL, Avinguda del Pla del Vent, 11A, 08970 Sant Joan Despí, Barcelona, Spain \\ b Department of Microbiology and Parasitology, Pharmacy Faculty, Universitat de Barcelona, Av. Joan XXIII s/n, 08028 Barcelona, Spain \\ ${ }^{c}$ Department of Statistics, Biology Faculty, Universitat de Barcelona, Av. Diagonal, 643, 08028 Barcelona, Spain \\ ${ }^{\mathrm{d}}$ GenIUL, Carrer de la Ciutat d'Asunción, 08030 Barcelona, Spain
}

\section{A R T I CLE IN F O}

Keywords:

Legionella

Viability PCR

PEMAX

Risk evaluation

\begin{abstract}
A B S T R A C T
Background: Viability quantitative Polymerase Chain Reaction (v-qPCR) is a recent analytical approach for only detecting live microorganisms by DNA amplification-based methods This approach is based on the use of a reagent that irreversibly fixes dead cells DNA. In this study, we evaluate the utility of v-qPCR versus culture method for Legionellosis risk management.

Methods: The present study was performed using 116 real samples. Water samples were simultaneously analysed by culture, v-qPCR and qPCR methods. Results were compared by means of a non-parametric test.

Results: In $11.6 \%$ of samples using both methods (culture method and v-qPCR) results were positive, in $50.0 \%$ of samples both methods gave rise to negative results. As expected, equivalence between methods was not observed in all cases, as in $32.1 \%$ of samples positive results were obtained by $\mathrm{v}-\mathrm{qPCR}$ and all of them gave rise to negative results by culture. Only in $6.3 \%$ of samples, with very low Legionella levels, was culture positive and v-qPCR negative. In $3.5 \%$ of samples, overgrowth of other bacteria did not allow performing the culture. When comparing both methods, significant differences between culture and v-qPCR were in the sampled belonging to the cooling towers-evaporative condensers group. The v-qPCR method detected greater presence and obtained higher concentrations of Legionella spp. ( $\mathrm{p}<0.001$ ). Otherwise, no significant differences between methods were found in the rest of the groups.

Conclusions: The v-qPCR method can be used as a quick tool to evaluate Legionellosis risk, especially in cooling towers-evaporative condensers, where this technique can detect higher levels than culture. The combined interpretation of PCR results along with the ratio of live cells is proposed as a tool for understanding the sample context and estimating the Legionellosis risk potential according to 4 levels of hierarchy.
\end{abstract}

\section{Introduction}

The genus Legionella comprises at least 61 species (tp://www. bacterio.net/legionella.html), 22 of them being associated to human disease (Winn, 2015). The most common pathogenic species is L. pneumophila serogroup 1 and is responsible for up to $80 \%$ of Legionellosis cases (Stout and $\mathrm{Yu}, 1997)$.

In nature, the genus Legionella can be considered ubiquitous in continental water environments and in man-made ecosystems; also can exist in appropriate environmental conditions that allow its proliferation. Respiratory infection by Legionella pneumophila (LP) is mainly attributed to inhalation of contaminated water aerosols produced by such

\footnotetext{
* Corresponding author.

Email address: fcodony@geniul.com (F. Codony)
}

systems and the aspiration of contaminated water has also been proposed as a possible mechanism of transmission (Yu, 1993).

Epidemiological data shows that Legionellosis outbreaks are related to cooling towers or hot water systems in big buildings as hotels and hospitals (Heymann, 2004). Nevertheless other man-made sources are related with infection, such as nebulizers (Woo et al., 1992), humidifiers (Endo and Ito, 2009), ornamental fountains (O'Loughlin et al., 2007), whirlpool spas (Benkel et al., 2000), water-birth baths (Franzin et al., 2004), ice-making machines, and domestic water blasters (Simmons et al., 2008). In addition, its presence is well known in dental units (Singh and Coogan, 2005) and also in rainwater on roads (Sakamoto et al., 2009). Therefore, virtually all man-made ecosystems containing water and with a capacity to disseminate may be related with Legionellosis risk. 
As a general rule, for preventing Legionella transmission or minimizing water system colonization, total heterotrophic counts are only available as process indicators. Likewise, temperature and disinfectant level are key factors for control. From the practical management of water systems, a microbial indicator or model organisms correlated with the occurrence of Legionella do not exist. For this reason, in order to measure the risk of Legionellosis, it is necessary to perform direct analysis, by culture, which requires 10 days to confirm its presence or absence (ISO 11731, 1998).

Hence, much attention has been paid to alternative methods to culture such as quantitative PCR (qPCR) and immunomagnetic separation (IMS) (Albalat et al., 2014). In both cases, commercial solutions are now available with external validation that demonstrate their potential. However, the present challenge is to find a good correlation among the information generated by non-culture based methods and the current management criteria based on culture results (Díaz-Flores et al., 2015).

At this stage, the main weakness of qPCR methods is their lack of specificity for distinguishing between dead and live cells. The development of viability qPCR (v-qPCR) procedures that only detect DNA from live cells, with 'live' meaning with intact cell membrane, are changing the scenario (Delgado-Viscogliosi et al., 2009; Ditommaso et al., 2015).

By means of v-qPCR, today it is possible to detect the levels of live cells quickly, obtaining a direct measure of pathogen levels in a few hours. Although in in vitro experiments it is possible to obtain very good correlations between culture and v-qPCR methods, the practical experience dictates the use of additional strategies in order to control the bias for minimizing false positive results (Fittipaldi et al., 2011; Agustí et al., 2017).

According to a previously published approach (Fittipaldi et al., 2011), together with a newly optimized v-qPCR workflow (Agustí et al., 2017), herein we propose the use of absolute quantification results along with the ratio of live cells as tools for understanding the sample context and estimating Legionellosis risk.

In this work, various water samples from different sources have been simultaneously analysed by standard culture procedures and v-qPCR, with the aim of evaluating the potential of $\mathrm{v}-\mathrm{qPCR}$ as a tool for managing the prevention and control of Legionellosis.

\section{Methods}

\subsection{Materials and methods}

\subsubsection{Collection of water samples}

During an 18-month period, a total of 116 water samples from different sampling points and buildings were analysed by Aconsa-Lab (Barcelona, Spain). Samples were categorized into 4 groups: 26 cooling towers and 12 evaporative condensers ( $n=46$ samples), 12 hot water systems ( $\mathrm{n}=19$ samples), 12 cold water systems and 10 nebulizers ( $\mathrm{n}=29$ samples), and others, 13 mainly fire-fighting water systems (tank reservoirs) and 9 swimming pools ( $\mathrm{n}=22$ samples).

Throughout this study 22 cooling towers were sampled once, three were sampled twice, and one was sampled three times. Regarding the evaporative condensers nine were sampled once and three were sampled twice. All the other systems were sampled once although there was more than one sampling point in some of them.

Water samples of $1 \mathrm{~L}$ were collected aseptically in sterile plastic containers containing sodium thiosulphate $(10 \% \mathrm{w} / \mathrm{v})$ and were transported at temperatures between 6 and $18{ }^{\circ} \mathrm{C}$ and shielded from the exposure to light. The transport preferably took less than $24 \mathrm{~h}$ but never more than $48 \mathrm{~h}$. Samples were received by the laboratory and stored at $3-7^{\circ} \mathrm{C}$ until needed, always within 24-48 h after sampling.

\subsubsection{Quantification of Legionella using culture method}

Culture-based assays for detecting and quantifying Legionella were conducted according to the reference culture method (ISO 11731, 1998) at an ISO 17025 accredited laboratory (cert. number: ENAC,962/ LE1805). Briefly, $1 \mathrm{~L}$ of water was filtered $(0.45 \mu \mathrm{m}$ pore-size Nylon filter, Pall Corporation, NY, USA) and resuspended in $5 \mathrm{~mL}$ of Ringer $1 / 40$ by vortexing for $10 \mathrm{~min}$. Two $1 \mathrm{~mL}$ aliquots were heat-treated $\left(50{ }^{\circ} \mathrm{C}\right.$ for $30 \mathrm{~min}$ ) or acid-treated ( $\mathrm{HCl}-\mathrm{ClK}$ buffer according to ISO 11731, pH 2.2 for $5 \mathrm{~min}$ ). Aliquots of $100 \mu \mathrm{l}$ of untreated, heat- and acid-treated specimens were plated onto selective agar for Legionella, Glycine-Vancomycin-Polymyxin and Cycloheximide agar (GVPC) (Reactivos para Diagnóstico, S.L., Barcelona, Spain). The plates were incubated at $36 \pm 2{ }^{\circ} \mathrm{C}$ for 10 days and read from day 4 with a stereo microscope. Presumed Legionella colonies were subcultured on Buffered Charcoal Yeast Extract media (with cysteine) (BCYE) and Nutrient Agar (cysteine-free) media (Reactivos para Diagnóstico, S.L., Barcelona, Spain) and incubated at $36 \pm 2{ }^{\circ} \mathrm{C}$ for $48-72 \mathrm{~h}$. The presence of Legionella spp. was considered positive when there were growths in BCYE but not in nutrient agar. The Legionella colonies were counted and the result was given as colony-forming units per litre $(\mathrm{cfu} / \mathrm{L})$. The recovery rate for this procedure is usually $35-65 \%$. Each sample batch contained a process negative control sample. The theoretical detection limit for culture was $50 \mathrm{cfu} / \mathrm{L}$.

\subsubsection{Quantification of viable Legionella using $v-q P C R$ triple approach}

A triple aliquot analysis approach was used with $500 \mu \mathrm{L}$ from the concentrated water sample (Fittipaldi et al., 2011) in order to detect: (1) viable cells, (2) false positive results, and (3) total level of cells. The first aliquot (1) was directly treated with PEMAX ${ }^{\mathrm{TM}}$ monodoses (Std. Buffer) (GenIUL, Barcelona, Spain). Briefly, the microtubes were placed in a Dark Box system (GenIUL) for dark incubation at $37{ }^{\circ} \mathrm{C}$ for $20 \mathrm{~min}$. Then, the sample was collected in a new polypropylene tube and was photo-activated at $100 \%$ for $15 \mathrm{~min}$ in a PhAST Blue system (GenIUL) (Agustí et al., 2017). The second aliquot (2) was exposed to heat treatment at $85{ }^{\circ} \mathrm{C}$ for $30 \mathrm{~min}$ in order to obtain a dead cell aliquot. After that, the bacterial suspension was treated with PEMAX ${ }^{\mathrm{TM}}$ monodoses (Std. Buffer), following the protocol described above. The third aliquot (3) was only concentrated by centrifugation $(14,000 \mathrm{~g}$ for $5 \mathrm{~min}$ ) using a minicentrifuge (Minispin Plus-Eppendorf, Hamburg, Germany) and discarding the supernatant to obtain a pellet. Each sample batch contained a process negative control sample. The conversion factor $\mathrm{x} 28$ between culture and PCR was selected according to Ditommaso et al. (2015).

\subsubsection{DNA purification and $P C R$}

In all cases, DNA was purified using the V-DNA reagent (GenIUL), according to the manufacturer's instructions. Following DNA purification, the samples were analysed by qPCR on the Mx3005P Real-Time PCR Platform (Agilent Technologies, Santa Clara, CA, USA). Amplifications and quantifications were made using the Legionella spp. qPCR detection kit (GenIUL). The PCR Kit meets the specification of ISO 12869:2012. Five microlitres of each extracted sample were used in the PCR reaction, following the cycling conditions: $15 \mathrm{~min}$ at $95^{\circ} \mathrm{C}, 45 \mathrm{cy}$ cles of $15 \mathrm{~s}$ at $95{ }^{\circ} \mathrm{C}, 30 \mathrm{~s}$ at $55^{\circ} \mathrm{C}$, and $30 \mathrm{~s}$ at $72{ }^{\circ} \mathrm{C}$ followed by data acquisition at $82{ }^{\circ} \mathrm{C}$ during $20 \mathrm{~s}$, and finally a melting temperature ramp from $65{ }^{\circ} \mathrm{C}$ to $95^{\circ} \mathrm{C}$ at $0.1{ }^{\circ} \mathrm{C} / \mathrm{s}$.

Additionally, for each amplification round, a negative (RNase-Free water) and a positive control (Standard DNA supplied in the kit) were included. Besides reagents and enzyme for the detection of Legionella spp. target sequence, the PCR mix also contained an internal control to identify reaction inhibition. Likewise, external standard curves for 
quantification were also provided in the same commercial kit. The qPCR data were analysed using MxPro Analysis Software version 4.1 (Agilent Technologies). With the estimation of the total and viable Legionella genome units (GU) levels the percentage of live cells could be calculated (\% live cells level $=[($ theoretical live cells GU - false positive cells GU)/total GU] $\times 100$ ). The theoretical limit of detection of this qPCR method was $1200 \mathrm{GU} / \mathrm{L}$.

\subsubsection{Statistical analysis}

In each sample group, results were categorized in 3 levels according to culture and v-qPCR results: no detection (detection limit $<50 \mathrm{cfu} /$ $\mathrm{L}$ and $<1200 \mathrm{GU} / \mathrm{L}$ ), positive detection of medium-low levels ( $<1000 \mathrm{cfu} / \mathrm{L}$ and $<28,000 \mathrm{GU} / \mathrm{L}$ ), positive detection of high levels ( $>1000 \mathrm{cfu} / \mathrm{L}$ and $>28000 \mathrm{GU} / \mathrm{L}$ ). Results were compared by means of a non-parametric test (Kruskal-Wallis rank analysis) in order to analyse the effectiveness of the counting methods according to the sample source. Following the rejection of the results of the Kruskal-Wallis test, a non-parametric (Dunn All-Pairs test) was performed to compare between groups as a "post hoc" test, based on rank sums. A chi-square test for independence was performed to analyse the relationship between method and positive detection. In all tests a level of significance alpha $=0.05$ was considered.

\section{Results}

A total of 116 water samples were simultaneously analysed by culture, v-qPCR and qPCR methods. The correspondence between results obtained is summarized in Table 1 . In 4 samples ( 2 cooling towers, 1 evaporative condenser and 1 hot water systems), which were positive by qPCR and v-qPCR, culture analysis was not possible due to overgrowth of interfering microorganisms. These results were not considered for the statistical analysis. In the culture analysis, in $82.1 \%$ of the samples $L e$ gionella spp. was not detected (- $<50 \mathrm{cfu} / \mathrm{L})$, while $13.4 \%$ of the samples had a medium-low level and $4.5 \%$ a high level was observed. In this case, it is important to note that the 4 samples had high Legionella levels, from $3.0 \mathrm{E}+03$ to $1.2 \mathrm{E}+06 \mathrm{GU} / \mathrm{L}$. When the samples were analysed by v-qPCR, $56.3 \%$ were included in the no Legionella sp. detected level ( $<1200 \mathrm{GU} / \mathrm{L}$ ), 33.9\% were positive for medium-low levels, and 4.5\% were positive for high detection levels. In all samples, a higher proportion of positive results was found by v-qPCR than by the culture method $(\mathrm{p}<0.04)$

Table 2 shows the correlation between the results obtained using the two methods. In 13 samples (11.6\%) both methods (culture method and v-qPCR) gave rise to positive results, and in 56 samples both methods gave rise to negative results (50.0\%). In 7 samples (6.3\%), with a very low Legionella level, the culture was positive and v-qPCR was negative. As expected, equivalence between methods was not observed in all cases. In seven samples, (6.3\%) the culture was positive and v-qPCR was negative. Interestingly, 36 samples (32.1\%) were positive by v-qPCR but negative by culture. PCR inhibition was not detected in any negative samples.

Table 3 shows the results categorization in 3 levels for each sample group: No detection (detection limit $<50 \mathrm{cfu} / \mathrm{L}$ and $<1200 \mathrm{GU} /$ $\mathrm{L})$; positive detection with medium-low levels $(<1000 \mathrm{cfu} / \mathrm{L}$ and

Table 1

Qualitatitve summary of culture vs v-qPCR results $(\mathrm{n}=112)$.

\begin{tabular}{lllll}
\hline & & & \\
\hline & & + & - & \\
\hline \multirow{2}{*}{ Culture } & & & 7 & 20 \\
& + & 13 & 56 & 92 \\
& - & 36 & 63 & 112 \\
\hline
\end{tabular}

$<28000 \mathrm{GU} / \mathrm{L}$ ), and positive detection with high levels (>1000 cfu/ $\mathrm{L}$ and $>28000 \mathrm{GU} / \mathrm{L})$. When culture and v-qPCR were compared in each group, the only significant differences $(p<0.001)$ were found for cooling towers-evaporative condensers. The v-qPCR method detected a greater presence and obtained higher concentrations of Legionella spp. than culture $(\mathrm{p}<0.001)$. No significant differences between the two methods were found for the other groups.

\section{Discussion}

The limitations of the standard ISO 11731 (1998) culture method are highlighted by the inaccuracy in the results from different laboratories when real environmental samples are used. For this reason the use of qPCR methods for monitoring Legionella levels requires the adjustment of action and alert levels (Lee et al., 2011).

According to these weaknesses, nowadays the value of culture-based methods is under question for routine monitoring, at least in potable water systems (Whiley, 2017), although such a statement may be considered controversial by other authors (Collins and Walker, 2017). Our results also show that, at least for some of our samples, the use of the culture method does not guarantee appropriate risk management. Although a direct correlation between Legionella load and Legionellosis risk has not been demonstrated, the national and international guidelines recommend risk control and intervention based on the detected Legionella load (Ditommaso et al., 2015).

The technical basis of $\mathrm{v}$-qPCR remains linked to the concept that the entire DNA from dead cells can be neutralized by means of photo reactive dyes (Fig. 1a). However, the evidence is that the practical experience of researchers and most publications, if not all at present, shows another reality (Fittipaldi et al., 2012).

For this reason, a common sense approach is depicted in Fig. 1b, where the sample analysis is performed using a triple PCR analysis in three different sample aliquots. First of all, by applying a v-qPCR procedure in two aliquots, one of them heat-treated previously $\left(85^{\circ} \mathrm{C}\right.$, $30 \mathrm{~min}$ ), it is possible to obtain an estimation of viable Legionella levels in the sample, minimizing the impact of false positive detections. Secondly, analysing the third sample aliquot by conventional qPCR, the total Legionella levels in the sample are obtained. This estimation is also important because it is related to the context of the water system.

Several technical reasons could explain the presence of positive results by v-qPCR but negative for culture in 36 samples, all of them as a result of culture weakness. Since the current media for Legionellae isolation are not completely selective and incubation up to 10 days is required, it is very common that Legionella growth can be inhibited or masked by other microorganisms. Additionally, after different disinfection treatments, a low nutrient environment and flagellated life cycle or growth in amoeba can induce a viable but non-cultivable status (Whiley and Taylor, 2016). Finally, an additional source of bias may be the intra-amoeba status, during at least a large part of the Legionella cycle. It can also be responsible for a major bias since each intra-amoeba group, or related structures, can generate a unique colony (Dietersdorfer et al., 2016). Despite the methodological issues related with the ecological role of amoeba, on the other side of the coin, in vitro amoebal co-culture is a well-known approach to revert this status and to detect those Legionella inside amoeba (La Scola et al., 2001), although this approach is not very common in routine laboratories.

Most of the discordant samples (27/36) are from cooling towers-evaporative condensers (75\%), 5/36 from hot water systems, 1 from a cold water system and 3 from other systems. The water complexity in cooling towers and evaporative condensers, from the chemical and biological point of view, is reflected in the lower recovery obtained when the culture method is used.

Reviewing the context of some of the discordant samples, 13 of them belong to different sampling points from two different industries 
Table 2

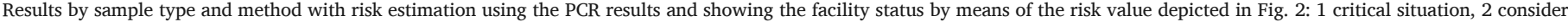
additional actions, 3 non-satisfactory, 4 satisfactory (n.d, non assesable due to interfering growth of other microorganisms; $+<1.2 \mathrm{E}+03$, presence less than detection limit).

\begin{tabular}{|c|c|c|c|c|}
\hline \multirow[t]{2}{*}{ Sample (water system) } & \multirow[t]{2}{*}{ Culture (cfu/L) } & \multicolumn{2}{|l|}{ PCR (GU/L) } & \multirow[b]{2}{*}{ Risk } \\
\hline & & qPCR & v-qPCR & \\
\hline \multirow[t]{46}{*}{ Cooling tower-Evaporative condenser } & $2.0 \mathrm{E}+02$ & $8.8 \mathrm{E}+03$ & $4.8 \mathrm{E}+03$ & 3 \\
\hline & $3.0 \mathrm{E}+02$ & $3.2 \mathrm{E}+04$ & $3.2 \mathrm{E}+03$ & 3 \\
\hline & $<5.0 \mathrm{E}+01$ & $7.2 \mathrm{E}+03$ & $3.0 \mathrm{E}+03$ & 3 \\
\hline & $4.0 \mathrm{E}+02$ & $3.5 \mathrm{E}+03$ & $5.0 \mathrm{E}+03$ & 3 \\
\hline & $<5.0 \mathrm{E}+01$ & $2.1 \mathrm{E}+03$ & $<1.2 \mathrm{E}+03$ & 4 \\
\hline & $<5.0 \mathrm{E}+01$ & $+<1.2 \mathrm{E}+03$ & $+<1.2 \mathrm{E}+03$ & 4 \\
\hline & $<5.0 \mathrm{E}+01$ & $1.2 \mathrm{E}+04$ & $<1.2 \mathrm{E}+03$ & 4 \\
\hline & $<5.0 \mathrm{E}+01$ & $<1.2 \mathrm{E}+03$ & $<1.2 \mathrm{E}+03$ & 4 \\
\hline & $<5.0 \mathrm{E}+01$ & $<1.2 \mathrm{E}+03$ & $<1.2 \mathrm{E}+03$ & 4 \\
\hline & $<5.0 \mathrm{E}+01$ & $<1.2 \mathrm{E}+03$ & $<1.2 \mathrm{E}+03$ & 4 \\
\hline & $2.0 \mathrm{E}+04$ & $1.2 \mathrm{E}+06$ & $1.6 \mathrm{E}+05$ & 1 \\
\hline & $<5.0 \mathrm{E}+01$ & $8.0 \mathrm{E}+03$ & $2.2 \mathrm{E}+03$ & 3 \\
\hline & $<5.0 \mathrm{E}+01$ & $4.8 \mathrm{E}+03$ & $+<1.2 \mathrm{E}+03$ & 4 \\
\hline & $<5.0 \mathrm{E}+01$ & $<1.2 \mathrm{E}+03$ & $<1.2 \mathrm{E}+03$ & 4 \\
\hline & n.d & $5.1 \mathrm{E}+04$ & $9.3 E+03$ & 3 \\
\hline & $<5.0 \mathrm{E}+01$ & $1.1 \mathrm{E}+04$ & $2.7 E+03$ & 3 \\
\hline & $<5.0 \mathrm{E}+01$ & $1.7 E+04$ & $2.7 \mathrm{E}+03$ & 3 \\
\hline & $<5.0 \mathrm{E}+01$ & $2.3 E+04$ & $1.9 \mathrm{E}+03$ & 3 \\
\hline & n.d & $2.5 \mathrm{E}+06$ & $1.2 \mathrm{E}+06$ & 1 \\
\hline & $<5.0 \mathrm{E}+01$ & $+<1.2 \mathrm{E}+03$ & $<1.2 \mathrm{E}+03$ & 4 \\
\hline & $<5.0 \mathrm{E}+01$ & $1.0 \mathrm{E}+05$ & $5.1 E+04$ & 1 \\
\hline & $<5.0 \mathrm{E}+01$ & $2.2 \mathrm{E}+04$ & $3.5 \mathrm{E}+03$ & 3 \\
\hline & $<5.0 \mathrm{E}+01$ & $1.7 E+04$ & $3.6 \mathrm{E}+03$ & 3 \\
\hline & $<5.0 \mathrm{E}+01$ & $2.9 \mathrm{E}+04$ & $9.2 \mathrm{E}+03$ & 3 \\
\hline & $<5.0 \mathrm{E}+01$ & $5.0 \mathrm{E}+03$ & $+<1.2 \mathrm{E}+03$ & 4 \\
\hline & $<5.0 \mathrm{E}+01$ & $3.6 \mathrm{E}+03$ & $+<1.2 \mathrm{E}+03$ & 4 \\
\hline & $<5.0 \mathrm{E}+01$ & $4.2 \mathrm{E}+03$ & $+<1.2 \mathrm{E}+03$ & 4 \\
\hline & $<5.0 \mathrm{E}+01$ & $2.1 E+04$ & $<1.2 \mathrm{E}+03$ & 4 \\
\hline & $<5.0 \mathrm{E}+01$ & $6.8 \mathrm{E}+03$ & $+<1.2 \mathrm{E}+03$ & 4 \\
\hline & $<5.0 \mathrm{E}+01$ & $3.7 E+03$ & $1.6 \mathrm{E}+03$ & 3 \\
\hline & $<5.0 \mathrm{E}+01$ & $5.2 \mathrm{E}+03$ & $2.9 \mathrm{E}+03$ & 3 \\
\hline & $<5.0 \mathrm{E}+01$ & $+<1.2 \mathrm{E}+03$ & $<1.2 \mathrm{E}+03$ & 4 \\
\hline & $<5.0 \mathrm{E}+01$ & $2.7 E+04$ & $+<1.2 \mathrm{E}+03$ & 2 \\
\hline & $<5.0 \mathrm{E}+01$ & $4.0 \mathrm{E}+06$ & $4.0 \mathrm{E}+03$ & 2 \\
\hline & $<5.0 \mathrm{E}+01$ & $<1.2 \mathrm{E}+03$ & $<1.2 \mathrm{E}+03$ & 4 \\
\hline & $<5.0 \mathrm{E}+01$ & $2.2 \mathrm{E}+05$ & $3.4 \mathrm{E}+04$ & 1 \\
\hline & $<5.0 \mathrm{E}+01$ & $1.7 E+06$ & $5.0 \mathrm{E}+05$ & 1 \\
\hline & n.d & $7.2 E+04$ & $3.0 \mathrm{E}+03$ & 3 \\
\hline & $6.0 \mathrm{E}+03$ & $6.4 \mathrm{E}+04$ & $1.6 \mathrm{E}+04$ & 3 \\
\hline & $<5.0 \mathrm{E}+01$ & $2.2 \mathrm{E}+04$ & $<1.2 \mathrm{E}+03$ & 4 \\
\hline & $<5.0 \mathrm{E}+01$ & $1.2 \mathrm{E}+06$ & $7.4 \mathrm{E}+04$ & 1 \\
\hline & $<5.0 \mathrm{E}+01$ & $2.0 \mathrm{E}+06$ & $1.2 \mathrm{E}+06$ & 1 \\
\hline & $<5.0 \mathrm{E}+01$ & $9.6 \mathrm{E}+04$ & $4.0 \mathrm{E}+04$ & 1 \\
\hline & $<5.0 \mathrm{E}+01$ & $7.8 \mathrm{E}+05$ & $3.4 \mathrm{E}+05$ & 1 \\
\hline & $<5.0 \mathrm{E}+01$ & $1.8 \mathrm{E}+06$ & $2.7 E+05$ & 1 \\
\hline & $<5.0 \mathrm{E}+01$ & $8.3 E+04$ & $2.3 \mathrm{E}+05$ & 1 \\
\hline \multirow[t]{19}{*}{ Domestic hot water } & $<5.0 \mathrm{E}+01$ & $<1.2 \mathrm{E}+03$ & $<1.2 \mathrm{E}+03$ & 4 \\
\hline & $<5.0 \mathrm{E}+01$ & $2.4 \mathrm{E}+04$ & $9.8 \mathrm{E}+03$ & 3 \\
\hline & n.d & $9.6 \mathrm{E}+03$ & $3.6 \mathrm{E}+03$ & 3 \\
\hline & $2.5 \mathrm{E}+02$ & $<1.2 \mathrm{E}+03$ & $<1.2 \mathrm{E}+03$ & 4 \\
\hline & $<5.0 \mathrm{E}+01$ & $<1.2 \mathrm{E}+03$ & $<1.2 \mathrm{E}+03$ & 4 \\
\hline & $<5.0 \mathrm{E}+01$ & $<1.2 \mathrm{E}+03$ & $<1.2 \mathrm{E}+03$ & 4 \\
\hline & $<5.0 \mathrm{E}+01$ & $+<1.2 \mathrm{E}+03$ & $+<1.2 \mathrm{E}+03$ & 4 \\
\hline & $+<5.0 \mathrm{E}+01$ & $+<1.2 \mathrm{E}+03$ & $+<1.2 \mathrm{E}+03$ & 4 \\
\hline & $<5.0 \mathrm{E}+01$ & $+<1.2 \mathrm{E}+03$ & $+<1.2 \mathrm{E}+03$ & 4 \\
\hline & $<5.0 \mathrm{E}+01$ & $8.9 \mathrm{E}+03$ & $7.4 \mathrm{E}+03$ & 3 \\
\hline & $<5.0 \mathrm{E}+01$ & $1.1 \mathrm{E}+04$ & $9.7 E+03$ & 3 \\
\hline & $4.0 \mathrm{E}+02$ & $1.4 \mathrm{E}+03$ & $<1.2 \mathrm{E}+03$ & 4 \\
\hline & $<5.0 \mathrm{E}+01$ & $<1.2 \mathrm{E}+03$ & $<1.2 \mathrm{E}+03$ & 4 \\
\hline & $<5.0 \mathrm{E}+01$ & $<1.2 \mathrm{E}+03$ & $<1.2 \mathrm{E}+03$ & 4 \\
\hline & $<5.0 \mathrm{E}+01$ & $<1.2 \mathrm{E}+03$ & $<1.2 \mathrm{E}+03$ & 4 \\
\hline & $<5.0 \mathrm{E}+01$ & $<1.2 \mathrm{E}+03$ & $<1.2 \mathrm{E}+03$ & 4 \\
\hline & $<5.0 \mathrm{E}+01$ & $<1.2 \mathrm{E}+03$ & $<1.2 \mathrm{E}+03$ & 4 \\
\hline & $<5.0 \mathrm{E}+01$ & $+<1.2 \mathrm{E}+03$ & $+<1.2 \mathrm{E}+03$ & 4 \\
\hline & $<5.0 \mathrm{E}+01$ & $<1.2 \mathrm{E}+03$ & $<1.2 \mathrm{E}+03$ & 4 \\
\hline \multirow[t]{3}{*}{ Domestic cold water } & $<5.0 \mathrm{E}+01$ & $<1.2 \mathrm{E}+03$ & $<1.2 \mathrm{E}+03$ & 4 \\
\hline & $7.0 \mathrm{E}+02$ & $<1.2 \mathrm{E}+03$ & $<1.2 \mathrm{E}+03$ & 4 \\
\hline & $<5.0 \mathrm{E}+01$ & $<1.2 \mathrm{E}+03$ & $<1.2 \mathrm{E}+03$ & 4 \\
\hline
\end{tabular}


Table 2 (Continued)

\begin{tabular}{|c|c|c|c|c|}
\hline \multirow[t]{2}{*}{ Sample (water system) } & \multirow[t]{2}{*}{ Culture (cfu/L) } & \multicolumn{3}{|l|}{ PCR (GU/L) } \\
\hline & & $\mathrm{qPCR}$ & v-qPCR & Risk \\
\hline & $<5.0 \mathrm{E}+01$ & $<1.2 \mathrm{E}+03$ & $<1.2 \mathrm{E}+03$ & 4 \\
\hline & $<5.0 \mathrm{E}+01$ & $+<1.2 \mathrm{E}+03$ & $<1.2 \mathrm{E}+03$ & 4 \\
\hline & $<5.0 \mathrm{E}+01$ & $+<1.2 \mathrm{E}+03$ & $<1.2 \mathrm{E}+03$ & 4 \\
\hline & $<5.0 \mathrm{E}+01$ & $+<1.2 \mathrm{E}+03$ & $<1.2 \mathrm{E}+03$ & 4 \\
\hline & $<5.0 \mathrm{E}+01$ & $<1.2 \mathrm{E}+03$ & $<1.2 \mathrm{E}+03$ & 4 \\
\hline & $<5.0 \mathrm{E}+01$ & $<1.2 \mathrm{E}+03$ & $<1.2 \mathrm{E}+03$ & 4 \\
\hline & $<5.0 \mathrm{E}+01$ & $<1.2 \mathrm{E}+03$ & $<1.2 \mathrm{E}+03$ & 4 \\
\hline & $4.0 \mathrm{E}+02$ & $3.8 \mathrm{E}+04$ & $8.6 \mathrm{E}+03$ & 3 \\
\hline & $<5.0 \mathrm{E}+01$ & $<1.2 \mathrm{E}+03$ & $<1.2 \mathrm{E}+03$ & 4 \\
\hline & $<5.0 \mathrm{E}+01$ & $<1.2 \mathrm{E}+03$ & $<1.2 \mathrm{E}+03$ & 4 \\
\hline & $<5.0 \mathrm{E}+01$ & $<1.2 \mathrm{E}+03$ & $<1.2 \mathrm{E}+03$ & 4 \\
\hline & $<5.0 \mathrm{E}+01$ & $<1.2 \mathrm{E}+03$ & $<1.2 \mathrm{E}+03$ & 4 \\
\hline & $<5.0 \mathrm{E}+01$ & $<1.2 \mathrm{E}+03$ & $<1.2 \mathrm{E}+03$ & 4 \\
\hline & $<5.0 \mathrm{E}+01$ & $<1.2 \mathrm{E}+03$ & $<1.2 \mathrm{E}+03$ & 4 \\
\hline & $<5.0 \mathrm{E}+01$ & $+<1.2 \mathrm{E}+03$ & $+<1.2 \mathrm{E}+03$ & 4 \\
\hline & $4.0 \mathrm{E}+02$ & $1.5 \mathrm{E}+03$ & $<1.2 \mathrm{E}+03$ & 4 \\
\hline & $<5.0 \mathrm{E}+01$ & $<1.2 \mathrm{E}+03$ & $<1.2 \mathrm{E}+03$ & 4 \\
\hline & $<5.0 \mathrm{E}+01$ & $<1.2 \mathrm{E}+03$ & $<1.2 \mathrm{E}+03$ & 4 \\
\hline & $<5.0 \mathrm{E}+01$ & $<1.2 \mathrm{E}+03$ & $<1.2 \mathrm{E}+03$ & 4 \\
\hline & $<5.0 \mathrm{E}+01$ & $<1.2 \mathrm{E}+03$ & $<1.2 \mathrm{E}+03$ & 4 \\
\hline & $<5.0 \mathrm{E}+01$ & $<1.2 \mathrm{E}+03$ & $<1.2 \mathrm{E}+03$ & 4 \\
\hline & $<5.0 \mathrm{E}+01$ & $<1.2 \mathrm{E}+03$ & $<1.2 \mathrm{E}+03$ & 4 \\
\hline & $<5.0 \mathrm{E}+01$ & $1.6 \mathrm{E}+04$ & $<1.2 \mathrm{E}+03$ & 4 \\
\hline & $<5.0 \mathrm{E}+01$ & $<1.2 \mathrm{E}+03$ & $<1.2 \mathrm{E}+03$ & 4 \\
\hline & $<5.0 \mathrm{E}+01$ & $<1.2 \mathrm{E}+03$ & $<1.2 \mathrm{E}+03$ & 4 \\
\hline & $<5.0 \mathrm{E}+01$ & $<1.2 \mathrm{E}+03$ & $<1.2 \mathrm{E}+03$ & 4 \\
\hline \multirow[t]{22}{*}{ Other (swimming pool. fire-fighting water) } & $<5.0 \mathrm{E}+01$ & $<1.2 \mathrm{E}+03$ & $<1.2 \mathrm{E}+03$ & 4 \\
\hline & $<5.0 \mathrm{E}+01$ & $+<1.2 \mathrm{E}+03$ & $+<1.2 \mathrm{E}+03$ & 4 \\
\hline & $<5.0 \mathrm{E}+01$ & $+<1.2 \mathrm{E}+03$ & $+<1.2 \mathrm{E}+03$ & 4 \\
\hline & $<5.0 \mathrm{E}+01$ & $<1.2 \mathrm{E}+03$ & $<1.2 \mathrm{E}+03$ & 4 \\
\hline & $<5.0 \mathrm{E}+01$ & $1.4 \mathrm{E}+04$ & $<1.2 \mathrm{E}+03$ & 4 \\
\hline & $2.0 \mathrm{E}+02$ & $2.1 \mathrm{E}+05$ & $1.8 \mathrm{E}+05$ & 1 \\
\hline & $4.5 \mathrm{E}+02$ & $<1.2 \mathrm{E}+03$ & $<1.2 \mathrm{E}+03$ & 4 \\
\hline & $<5.0 \mathrm{E}+01$ & $<1.2 \mathrm{E}+03$ & $<1.2 \mathrm{E}+03$ & 4 \\
\hline & $<5.0 \mathrm{E}+01$ & $<1.2 \mathrm{E}+03$ & $<1.2 \mathrm{E}+03$ & 4 \\
\hline & $<5.0 \mathrm{E}+01$ & $<1.2 \mathrm{E}+03$ & $<1.2 \mathrm{E}+03$ & 4 \\
\hline & $<5.0 \mathrm{E}+01$ & $<1.2 \mathrm{E}+03$ & $<1.2 \mathrm{E}+03$ & 4 \\
\hline & $<5.0 \mathrm{E}+01$ & $<1.2 \mathrm{E}+03$ & $<1.2 \mathrm{E}+03$ & 4 \\
\hline & $2.0 \mathrm{E}+02$ & $<1.2 \mathrm{E}+03$ & $<1.2 \mathrm{E}+03$ & 4 \\
\hline & $<5.0 \mathrm{E}+01$ & $<1.2 \mathrm{E}+03$ & $<1.2 \mathrm{E}+03$ & 4 \\
\hline & $1.0 \mathrm{E}+04$ & $1.2 \mathrm{E}+05$ & $1.2 \mathrm{E}+04$ & 1 \\
\hline & $<5.0 \mathrm{E}+01$ & $<1.2 \mathrm{E}+03$ & $<1.2 \mathrm{E}+03$ & 4 \\
\hline & $1.0 \mathrm{E}+03$ & $2.1 \mathrm{E}+04$ & $2.9 \mathrm{E}+03$ & 3 \\
\hline & $2.0 \mathrm{E}+02$ & $+<1.2 \mathrm{E}+03$ & $+<1.2 \mathrm{E}+03$ & 2 \\
\hline & $6.5 E+02$ & $2.9 \mathrm{E}+04$ & $3.9 \mathrm{E}+03$ & 3 \\
\hline & $9.8 \mathrm{E}+04$ & $2.6 \mathrm{E}+04$ & $1.3 \mathrm{E}+03$ & 3 \\
\hline & $<5.0 \mathrm{E}+01$ & $+<1.2 \mathrm{E}+03$ & $+<1.2 \mathrm{E}+03$ & 4 \\
\hline & $2.0 \mathrm{E}+02$ & $+<1.2 \mathrm{E}+03$ & $<1.2 \mathrm{E}+03$ & 4 \\
\hline
\end{tabular}

(7 and 6) and in both cases these samples showed very high v-qPCR counts. In both industries the biocide used was based on isothiazolinones. These biocides are effective in vitro against Legionella, however the current dosage concentrations when used with other chemical additives do not suffice for the disinfection of planktonic protozoa, the main Legionella reservoir (Critchley and Bentham, 2009). Additionally, in at least one of these industries, fast-growing microorganisms, which may often affect microbial cultures, might also affect Legionella detection. In this case the results of this study suggest a latent problem in these systems that would need a special approach by the owner.

However, the presumptive false negative result by PCR $(n=7)$ can be explained by two different approaches. Firstly, this case corresponds to samples with a low contamination level, lower than the detection limit of qPCR methods. Under the experimental conditions used in this study the detection limits of the qPCR and culture procedures were $1200 \mathrm{GU} / \mathrm{L}$ and $50 \mathrm{cfu} / \mathrm{L}$, respectively. Secondly, as the Legionella species were not confirmed by serological methods, the result could correspond to real false positive detection by culture. Since it has been described that some members of Chitinophagaceae can grow on GVPC agar and cause false positive detections, this possibility cannot be ruled out (Borges et al., 2012).

In the coming years the evolution of the current alternative protocols based on PCR to replace standard and optimized protocols will probably be a reality, which will generate robust and accurate results. However, at this point it is important to focus beyond the technical status and try to interpret the results of $\mathrm{v}$-qPCR methods and how to apply the information generated by them to the management of water systems.

Currently, with less than five hours, v-qPCR methods can provide a notion as to the situation of each sampling point in most cases. As an initial approach, at least four different scenarios can be hypothesized (Fig. 2). However it is essential to remark the importance of having some knowledge of the system, its previous history and context of use (hospital hot water, cooling tower, irrigation water, etc.), and the biocide and chemical additives used. Risk evaluation in most cases needs a 
Table 3

Results grouped by sample type and Legionella levels (-, no detection).

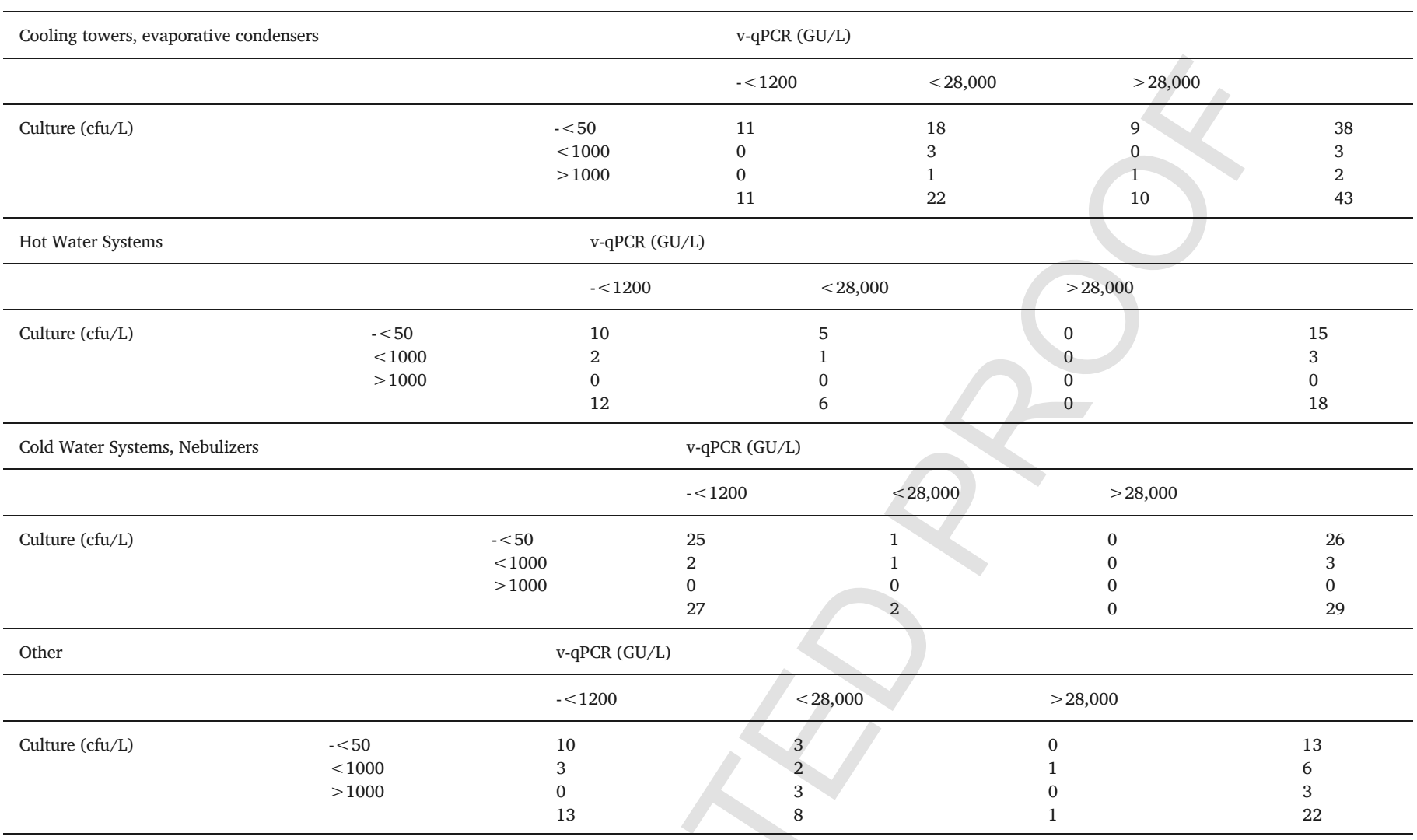

\section{Theoretical approach}

PCR

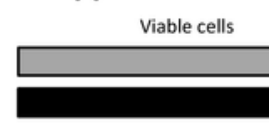

Reality

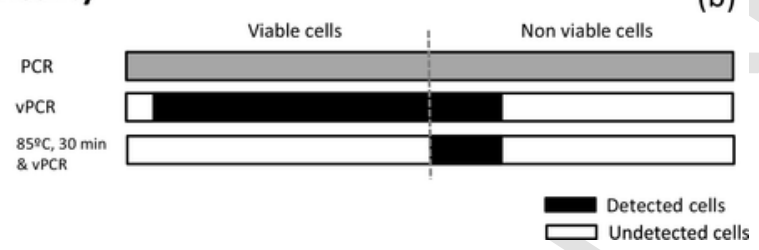

Fig. 1. Experimental approach. Diagrams showing the information obtained by PCR vs viability PCR (v-qPCR) considering the theoretical approach (a) and the reality (b). Black bars show the fraction of cells detected and white bars show the undetected fraction. V-qPCR has several analytical biases (b), one portion of DNA from live cells can become neutralized (false negative), and one portion of DNA from dead cells may not be neutralized (false positive). The current viability PCR dyes, such PEMAX and PMA, render the false negative portion insignificant. In order to estimate the false positive portion, the sample is heat-treated in order to kill all cells.

deep understanding of the context. As a quick tool the results can be categorized into 4 levels as follows.

First of all (1), the scenario can be the presence of high levels of mostly live Legionella. This case may pose a major threat; therefore the system requires immediate action.

Second (2), if there high levels exist but most of the pathogens are dead, it could mean that in the recent history of the system there were high levels of Legionella, which can have different meanings. After an immediate disinfection procedure the presence of low levels of live cells can be related to the good mitigation of the problem. However, if

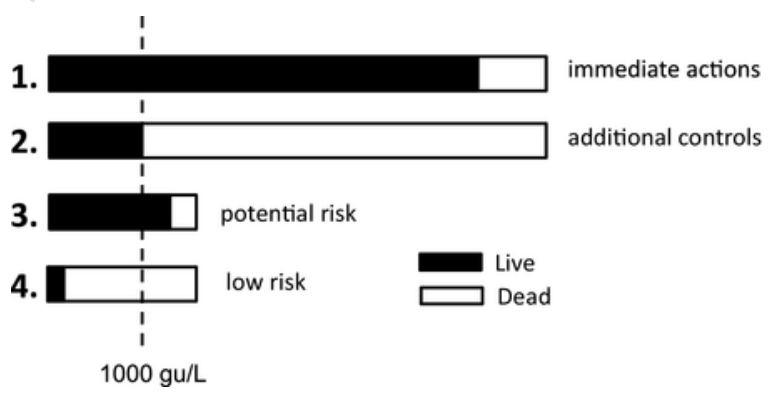

Fig. 2. Diagram for risk evaluation. Black bars show the fraction of dead cells and white bars show the fraction of live cells. Long bars suggest high cell levels. Short bars suggest low contamination levels. (1) High cell levels with high proportions of live cells can be involved in cases of Legionellosis. The systems require immediate action. (2) High cell levels with a low proportion of live cells can suggest an incipient colonization or incomplete disinfection. The system requires additional controls,potential risk. (3) Low cell levels but most of them are alive. There is a risk of evolving up to (1). (4) Low cell levels and only a minimal fraction is alive. There is no risk of Leginellosis and the system is under control, low risk.

the situation is detected after some days of the disinfection, it may be related to incomplete disinfection (or inappropriate procedure with inadequate purging) and new regrowth. The actions implemented after results evaluation may depend on the system context.

Third (3), there are low levels but most of the pathogens are alive: probably the system does not pose an immediate treat. This situation may require additional surveillance, for example by means of complementary analysis by culture. This approach can allow identifying pathogenic species or serogroups, such as L. pneumophila serogroup 1.

Four (4), there are low levels but most of the pathogens are dead. This means that the system is well managed (4). 
The proposed 4-tier risk evaluation approach has been applied as a quick strategy for evaluating the potential risk status

The theory is clear, however at this stage, a cutting point between safety and risk levels should be defined since to date we have been managing water systems with a conceptual framework based on culture. According to the results of this study and our experience, we consider that this limit could probably be $1000 \mathrm{GU} / \mathrm{L}$. However, without clear infectious dose values it is difficult to determine what concentration can be considered safe (Whiley et al., 2014).

The current approach needs three individual PCR assays, which would add a significant workload and resources for a front-line testing laboratory and in terms of economical cost it can be considered a drawback. Since we have demonstrated that the false positive sample does not greatly affect the final results, we believe that, for routine management, the v-qPCR alone might prove sufficient.

While molecular methods measure genomic units, which can be comparable to total cell (qPCR) or live cell levels ( $\mathrm{v}$-qPCR), the culture approach estimates colony-forming units, thus both methods actually show different information. In practice, however, the technical staff tends to consider all the results using the same conceptual framework. This has been one of the drawbacks, but not the main one, for the implementation of molecular methods in risk management in water systems. Previous studies conducted with qPCR methods demonstrate a bias of several orders of magnitude between qPCR and culture (Fittipladi et al., 2010), and one additional persistent reality is that the qPCR also detects DNA from dead cells (Whiley, 2016). Although the bias can be managed by applying correction factors, the detection of DNA from dead cells introduces considerable uncertainty.

The v-qPCR methods demonstrate that this drawback could be overcome and to date, different works have demonstrated their feasibility (Delgado-Viscogliosi et al., 2009; Ditommaso et al., 2015). To our knowledge, the latest attempt to establish a conversion factor between qPCR, v-qPCR and culture was made by Ditommaso et al. (2015). In their work the authors suggested dividing the value expressed in GU 28 times to obtain a cfu estimation. However, a conversion factor like this needs more in-depth work to become a consensus, such as multicentre studies and in vitro experiments, in order to improve the understanding of the effect of different biocides. In our opinion, it is a reasonable estimation and is also coherent with our theoretical cutting point of 1000 GU/L. In this study our detection limit was $1200 \mathrm{GU} / \mathrm{L}$ and our quantification limit $3600 \mathrm{GU} / \mathrm{L}$, and according to the previous criteria this means that we were detecting 43 or $128 \mathrm{cfu} / \mathrm{L}$ respectively. Given that in our national regulation, as also occurs in other countries or technical guidelines, the regulatory value is $100 \mathrm{cfu} / \mathrm{L}$, the current $\mathrm{v}$-qPCR protocol is suitable for working in the appropriate range.

In previous works the feasibility of v-qPCR as an analytical tool for risk assessment has been questioned (Scaturro et al., 2016; Taylor et al., 2014). In the case of the former, a quick review of the Methods section reveals huge mistakes in inoculum preparation. Since incomplete heat treatment was applied to inactivate the cells, obviously the v-qPCR data were unsatisfactory. In the case of the latter, in the absence of correction factors for adjusting the bias as stated before, the authors suggested that their v-qPCR protocol was not operative, at least for biofilm samples.

At this stage, not only consensus and standard technical criteria are necessary for data analysis, but also good methodological practices in routine laboratories. The quality of results in molecular procedures is highly influenced by factors such as DNA normalization and the use of appropriate controls. In future scenarios, ISO17025 accreditation will yield more robust results and facilitate greater use of molecular techniques.

In this work, with a protocol that includes differential aliquot treatment, a bias correction of the DNA adhered to tube and the use of one effective viability dye mix, we have reduced the previous variability, even in real samples.

In this work not all types of water have been examined. Therefore, future studies should focus on evaluating the feasibly of the method for other samples, such as waste water and recycled water, which are complicated to analyse by culture.

In conclusion, we have demonstrated the potential of $\mathrm{v}$-qPCR as a tool for managing water systems and potentially ascertaining risk, and how the results can be used for creating a risk scale for managing water systems.

In our opinion, the complex and dynamic reality leads to the need to use the information generated by v-qPCR in a broad framework together with background information on each system.

\section{Disclosure statement}

We would like to declare author relationships that may be viewed as presenting a potential conflict of interests. Currently, Francesc Codony and Gemma Agustí are involved with GenIUL, which manufactures PCR products and vPCR reagents. Francesc Codony is also related, as an inventor, in several vPCR patents.

\section{Uncited reference \\ Yu and Stout (2010).}

\section{Acknowledgements}

The authors would like to thank and acknowledge Dr H. Whiley of the Faculty of Science \& Engineering, School of the Environment at Flinders University, for her kind technical review of this work.

\section{References}

Agustí, G., Fittipaldi, M., Codony, F., 2017. False-positive viability PCR results: an association with microtubes. Curr. Microbiol. https://doi.org/10.1007/s00284-016-1189-3. Albalat, G.R., Broch, B.B., Bono, M.J., 2014. Method modification of the Legipid ${ }^{\circledR}$ Legionella fast detection test kit. J. AOAC. Int. 97, 1403-1409.

Benkel, D.H., McClure, E.M., Woolard, D., Rullan, J.V., Miller G.B.Jr. Jenkins, S.R., Hershey, J.H., Benson, R.F., Pruckler, J.M., Brown, E.W., Kolczak, M.S., Hackler, R.L., Rouse, B.S., Breiman, R.F., 2000. Outbreak of Legionnaires' disease associated with a display whirlpool spa. Int. J. Epidemiol. 29, 1092-1098.

Borges, A., Simões, M., Martínez-Murcia, A., Saavedra, M., 2012. Detection of Legionella spp. In natural and man-made water systems using standard guidelines. J. Microbiol. Res. 2, 95-102.

Collins, S., Walker, J., 2017. Comments on whiley Legionella risk management and control in potable water systems: argument for the abolishment of routine testing. Int. J. Environ. Res. Public Health 14 (1), 12.

Critchley, M., Bentham, R., 2009. The efficacy of biocides and other chemical additives in cooling water systems in the control of amoebae. J. Appl. Microbiol. 106, 784-789.

Díaz-Flores, , Montero, J.C., Castro, F.J., Alejandres, E.M., Bayón, C., Solís, I., Fernández-Lafuente, R., Rodríguez, G., 2015. Comparing methods of determining Legionella spp. in complex water matrices. BMC Microbiol. 29 (15), 91.

Delgado-Viscogliosi, P., Solignac, L., Delattre, J.M., 2009. Viability PCR, a culture-independent method for rapid and selective quantification of viable Legionella pneumophila. Appl. Environ. Microbiol. 75, 3502-3512.

Dietersdorfer, E., Cervero-Aragó, S., Sommer, R., Kirschner, A.K., Walochnik, J., 2016. Optimized methods for Legionella pneumophila release from its Acanthamoeba hosts. BMC Microbiol. 16, 74.

Ditommaso, S., Ricciardi, E., Giacomuzzi, M., Rivera, S.R.A., Zotti, C.M., 2015. Legionella in water samples: how can you interpret the results obtained by quantitative PCR? Mol. Cell. Prob. 29, 7-12.

Endo, K., Ito, K., 2009. Case of Legionella pneumonia caused by a household humidifier. Nihon Kokyuki Gakkai Zasshi. 47, 388-392.

Fittipaldi, M., Codony, F., Adrados, B., Camper, A.K., Morató, J., 2011. Viable real-time PCR in environmental samples: can all data be interpreted directly?. Microb. Ecol. 61, 7-12.

Fittipaldi, M., Nocker, A., Codony, F., 2012. Progress in understanding preferential detection of live cells using viability dyes in combination with DNA amplification. J. Microbiol. Methods 91, 276-289.

Fittipladi, M., Codony, F., Morato, J., 2010. Comparison of conventional culture and real-time quantitative PCR using SYBR Green for detection of Legionella pneumophila in water samples. Water SA. 36 (4), 1-8. 
Franzin, L., Cabodi, D., Scolfaro, C., Gioannini, P., 2004. Microbiological investigations on a nosocomial case of Legionella pneumophila pneumonia associated with water birth and review of neonatal cases. Infez. Med. 12, 69-75.

Heymann, D.L., 2004. Control of Communicable Diseases Manual, 8th ed. American Public Health Association, United Book Press, Inc., Baltimore.

ISO 11731, 1998. Water Quality—Detection and Enumeration of Legionella. International Organization for Standardization, Geneva.

ISO/TS 12896, 2012. Water Quality_Detection and Quantification of Legionella Spp And/ or Legionella Pneumophila by Concentration and Genic Amplification by Quantitative Polymerase Chain Reaction (qPCR). International Organization for Standardization, Geneva.

La Scola, B., Mezi, L., Weiller, P.J., Raoult, D., 2001. Isolation of Legionella anisa using an amoebic coculture procedure. J. Clin. Microbiol. 39 (January (1)), 365-366.

Lee, J.V., Lai, S., Exner, M., Lenz, J., Gaia, V., Casati, S., Hartemann, P., Lück, C., Pangon, B., Ricci, M.L., Scaturro, M., Fontana, S., Sabria, M., Sánchez, I., Assaf, S., Surman-Lee, S., 2011. An international trial of quantitative PCR for monitoring Legionella in artificial water systems. J. Appl. Microbiol. 110 (4), 1032-1044.

O'Loughlin, R.E., Kightlinger, L., Werpy, M.C., Brown, E., Stevens, V., Hepper, C., Keane, T., Benson, R.F., Fields, B.S., Moore, M.R., 2007. Restaurant outbreak of Legionnaires' disease associated with a decorative fountain: an environmental and case-control study. BMC Infect. Dis. 9, 93.

Sakamoto, R., Ohno, A., Nakahara, T., Satomura, K., Iwanaga, S., Kouyama, Y., Kura F., Kato, N., Matsubayashi, K., Okumiya, K., Yamaguchi, K., 2009. Legionella pneumophila in rainwater on roads. Emerg. Infect. Dis. 15, 1295-1297.

Scaturro, M., Fontana, S., Dell'eva, I., Helfer, F., Marchio, M., Stefanetti, M.V., Cavallaro, M., Miglietta, M., Montagna, M.T., De Giglio, O., Cuna, T., Chetti, L., Sabattini, M.A Carlotti, M., Viggiani, M., Stenico, A., Romanin, E., Bonanni, E., Ottaviano, C.,
Franzin, L., Avanzini, C., Demarie, V., Corbella, M., Cambieri, P., Marone, P., Rota, M.C., Bella, A., Ricci, M.L., 2016. A multicenter study of viable PCR using propidium monoazide to detect Legionella in water samples. Diagn. Microbiol. Infect. Dis. 85, 283-288.

Simmons, G., Jury, S., Thornley, C., Harte, D., Mohiuddin, J., Taylor, M., 2008. Legionnaires' disease outbreak: a water blaster and roof-collected rainwater Systems. Water. Res. 42, 1449-1458.

Singh, T., Coogan, M.M., 2005. Isolation of pathogenic Legionella species and legionella-laden amoebae in dental unit waterlines. J. Hosp. Infect. 61, 257-262.

Stout, J.E., Yu, V.L., 1997. Legionellosis. N. Engl. J. Med.. 337, 682-687.

Taylor, M.J., Bentham, R.H., Ross, K.E., 2014. Limitations of using propidium monoazide with QPCR to discriminate between live and dead legionella in biofilm samples. Microbiol. Insights 7, 15-24.

Whiley, H., Taylor, M., 2016. Legionella detection by culture and QPCR: comparing apples and oranges. Crit. Rev. Microbiol. 42, 65-67.

Whiley, H., Keegan, A., Fallowfield, H., Ross, K., 2014. Uncertainties associated with assessing the public health risk from Legionella. Front. Microbiol. 5, 501.

Whiley, H., 2017. Legionella risk management and control in potable water systems: argument for the abolishment of routine testing. Int. J. Environ. Res. Public Health 14 (1) 12.

Winn, W.C., 2015. Legionella. Bergey's Manual of Systematics of Archaea and Bacteria. $1-44$

Woo, A.H., Goetz, A., Yu, V.L., 1992. Transmission of Legionella by respiratory equipment and aerosol generating devices. Chest 102, 1586-1590.

Yu, V.L., Stout, J.E., 2010. Legionella in an ice machine may be a sentinel for drinking water contamination. Infect. Control. Hosp. Epidemiol. 31, 317.

Yu, V.L., 1993. Could aspiration be the major mode of transmission for legionella?. Am. J. Med. 95, 13-15. 